\title{
Lúcio Costa e os jesuítas nas revistas do SPHAN (1937-1945)
}

\author{
Rogério Entringer*
}

Resumo Este artigo demonstra como os jesuítas e sua arquitetura (1549-1759), junto ao nome de Lúcio Costa, são recorrentes nos artigos das revistas do SPHAN entre 1937 e 1945. Defendemos a tese de que o SPHAN e seus intelectuais, entre eles Costa, por meio dessas revistas, utilizaram os signos dos jesuítas, tal como sua importância histórica na formação do Brasil e o valor patrimonial de sua arte e arquitetura, para permitir à sociedade estado-novista representar a si mesma, fundar uma identidade nacional pelo movimento moderno e delinear a ideia de uma República justificada pela história.

Palavras-chave: Lúcio Costa, arquitetura dos jesuítas, revistas SPHAN.

\section{Lúcio Costa and the jesuits in the SPHAN journals (1937-1945)}

Abstract This article demonstrates how the Jesuits and their architecture (1549-1759), along with the name of Lúcio Costa, are recurrent in SPHAN journals articles between 1937 and 1945. We defend the thesis that SPHAN and its intellectuals, among them Costa, by means of these journals, used the signs of the Jesuits, such as their historical importance in the formation of Brazil and the patrimonial value of their art and architecture, to enable New State society to represent itself, to found a national identity by the modern outline the idea of a republic justified by history.

Key words: Lúcio Costa, architecture of jesuits, SPHAN journals.

\section{Lúcio Costa y los jesuitas en las revistas del SPHAN (1937-1945)}

Resumen En este artículo se muestra cómo los jesuitas y su arquitectura (1549-1759), junto al nombre de Lúcio Costa, son recurrentes en los artículos de las revistas del SPHAN entre 1937 y 1945. Defendemos la tesis de que el SPHAN y sus intelectuales, entre ellos Costa, por medio de esas revistas, utilizaron los signos de los jesuitas, tal como su importancia histórica en la formación de Brasil y el valor patrimonial de su arte y arquitectura, para permitir a la sociedad estado-novio representar a sí misma, fundar una identidad nacional por el movimiento moderno y, delinear la idea de una República justificada por la historia.

Palavras clave: Lúcio Costa, arquitectura de los jesuitas, revistas SPHAN. 


\section{A arquitetura dos jesuítas nas revistas do SPHAN (1937-1945)}

O Serviço do Patrimônio Histórico e Artístico Nacional - SPHAN - abre sua série de revistas estampando logo na capa de seu primeiro exemplar de 1937 um desenho de Luís Saia da Igreja dos Jesuítas de São Pedro da Aldeia, um dos símbolos da formação histórica do Rio de Janeiro.

Nesse volume, Godofredo Filho em artigo intitulado Seminário de Belém da Cachoeira da Bahia, destaca "o aspecto severo, rude da expressão do conjunto" (REVISTA SPHAN, 1937, p.105). Godofredo Filho exalta a importância da Companhia de Jesus e sua arquitetura na formação histórica do Brasil quando diz que "não só na orla marítima, nas velhas cidades clássicas da colônia floresceu o gênio arquitetônico da Companhia" (REVISTA SPHAN, 1937, p.101). Godofredo evidencia que a escolha do lugar por parte dos jesuítas para a implantação de seus núcleos construtivos eram pensados voltados à pedagogia e o ensino próprio da Companhia, quando referindo-se ao Seminário de Belém da Cachoeira diz que "o local, pela sugestão do silêncio e agreste solitude, não poderia ser melhor para que o escolhesse a pedagogia jesuíta". Godofredo justifica o pioneirismo jesuítico e sua Ratio Studiorum no ensino brasileiro quando diz que "uma verdadeira universidade religiosa do Brasil colonial floresceu ali, naquele seminário de almas, o grande viveiro clássico das letras greco-latinas, a mais famosa escola de formação de nossas elites diretoras" (REVISTA SPHAN, 1937, p.104). Godofredo fecha seu artigo evidenciando a importância do patrimônio histórico deixado pelos jesuítas coloniais quando diz que o Seminário e sua Igreja "vale como um símbolo perfeito, relíquia que se não foi no grande naufrágio do resto" (REVISTA SPHAN, 1937, p.107).

Noronha Santos publica nessa revista o artigo intitulado A Igreja de São Francisco Xavier em Niterói destacando o partido das construções dos inacianos coloniais, dizendo que "aparência de cela claustral foram comumente construída pelos jesuítas em suas casas com paredes de grandes dimensões e pesadas portas" (REVISTA SPHAN, 1937, p.140).

Esse volume traz também um documentário fotográfico (há indícios de que foi feito pelo fotógrafo Erich Hess) da Igreja de São Pedro da Aldeia (RJ), destacando que sua fachada simples, pura, equilibrada e de boas proporções, são tipicamente derivada da arquitetura popular do Mediterrâneo" (REVISTA SPHAN, 1937, p.122).

*Rogério Entringer é Historiador, doutorando em Arquitetura e Urbanismo pelo Instituto de Arquitetura e Urbanismo USP, ORCID: <https://orcid.org/00000001-7988-1450>.
Nesse volume há um artigo do senhor Lucio Costa intitulado Documentação Necessária onde ele diz que "o engenhoso processo de que são feitas a arquitetura colonial barro armado com madeira - tem qualquer coisa do nosso concreto-armado" (REVISTA SPHAN, 1938, p.34). Ainda nesse artigo Lucio Costa parece estar na busca da tradição lusitana colonial para justificar a evolução da arquitetura moderna no Brasil quando refere-se a essa como "a procura não intencional de um equilíbrio plástico diferente" (REVISTA SPHAN, 1937, p.38). 
Figura 1: COSTA, Lucio. Desenhos sobre o Mobiliário Luso-brasileiro Setecentista e sobre o Mobiliário das Vanguardas Europeias Modernas. Fonte: Revista do SPHAN, 03 de 1939.
Na revista 02 de 1938, Alberto Lamego em artigo intitulado Solar do Colégio (Campos dos Goytacazes - RJ), diz que a arquitetura dos jesuítas "evoca o severo lineamento e a indobrável disciplina de Loyola, geometrizando pela sua rigidez dogmática a rebelde consciência do selvagem" (REVISTA SPHAN, 1938, p.22). Alberto Lamego diz que o pátio interno é "sólido, ladrilhado perpetuando o espírito monacal de outrora" . Lamego defende a importância histórica dos jesuítas quando diz que: "prova de tacanhíssima parcialidade e de completa ignorância dos nossos grandes historiadores, é o contestar-se a formidável influência do primitivo jesuíta na cimentação da nacionalidade brasileira" (REVISTA SPHAN, 1938, p.24). Nessa revista há também um artigo de Romulo Barreto de Almeida intitulado Capela de São José do Genipapo (BA) dizendo que essa capela "ao gosto jesuítico, é severa" (REVISTA SPHAN, 1938, p. 226).

Na revista 03 de 1939, Lucio Costa publica artigo intitulado Evolução do Mobiliário Luso-Brasileiro, onde ele cita e desenha mobiliários luso-brasileiros setecentista e os compara aos dos mestres modernos europeus como Le Corbusier e Mies Van der Rohe. Segundo Lucio Costa:

como nosso mobiliário seguiu sempre de perto, a evolução do móvel europeu e de-verá portanto, tradicionalmente, ainda agora, acompanhar as transformações produzidas pela técnica contemporânea, o que caracteriza aos poucos exemplos atuais de peças concebidas com espírito verdadeiramente moderno que se distinguem pela leveza, assim como o mobiliário setecentista, uma estabilidade perfeita e proporções ajustadas ao corpo. (REVISTA SPHAN, 1939, p, 160-161)

E assim como o mobiliário dos mestres da vanguarda moderna europeia, o mobiliário jesuítico colonial também era leve, simples, estável e, assim como suas construções, era concebido segundo as proporções humanas.
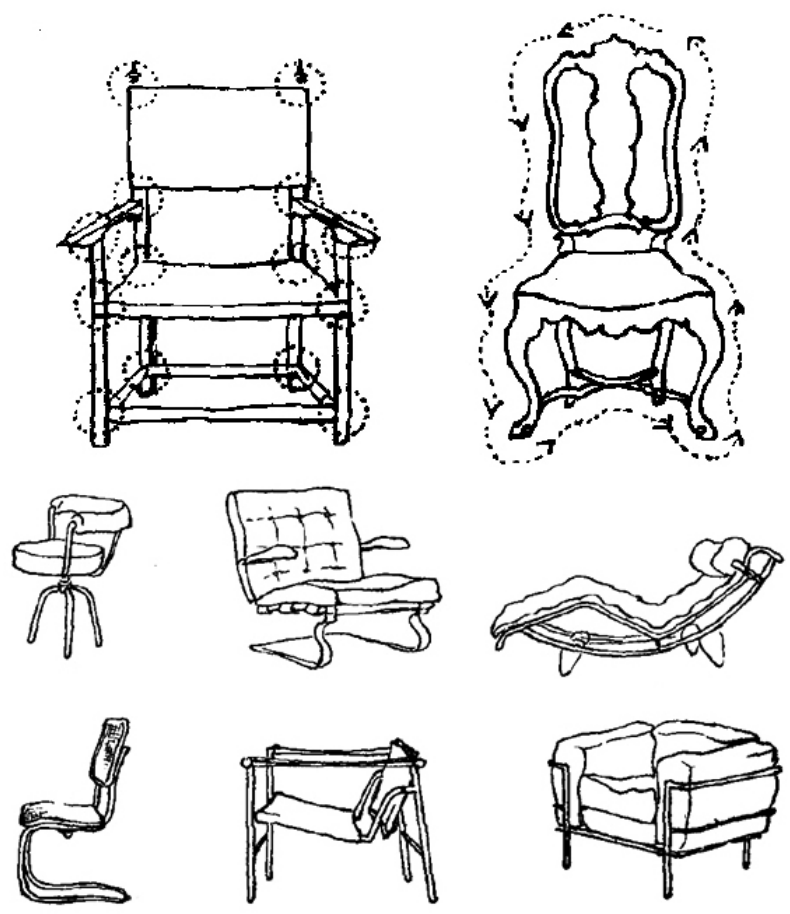

LE CORBUSIER, CHARLOTTR PERRIAND, MIES VAN DER ROHE, ETC. 
Na revista 04 de 1940, o artigo de Alberto Lamego intitulado Os Sete Povos das Missões não esconde também sua admiração e seu apreço pelo ditador do Brasil daquele tempo, bem como a exaltação ao Museu que seria construído pelo SPHAN encomendado ao arquiteto Lucio Costa quando diz:

agora que o grande estadista Getúlio Vargas que dirige a nação faz reviver das cinzas do passado os dias gloriosos dos Sete Povos das Missões, considerando monumentos históricos as suas igrejas em ruínas, determinando, por decreto, a sua restauração e a organização de um museu, na de São Miguel, para guarda das relíquias esparsas a elas pertencentes, que o tempo ainda não destruiu". (SPHAN, 1940, p.56)

Vale lembrar que Vargas nasceu em São Borja (RS), cidade fundada pela Companhia de Jesus no século XVII, e Alberto Lamego havia estudado em dois colégios jesuítas, o Colégio Campolide em Lisboa (Portugal), e no Colégio Saint Michel em Bruxelas (Bélgica).

Nesse volume aparece também o artigo de Maria de Lourdes Pontual intitulado A Sacristia da Catedral da Baía e A Posição da Igreja Primitiva dizendo que essa é dotada de uma "elegância sóbria" (REVISTA SPHAN, 1940, p.201). Pontual, que era funcionária do SPHAN e seu nome aparece em grande número nos processos de tombamentos desse período, descreve que o "partido seguido pelos jesuítas é em quadra" (REVISTA SPHAN, 1940, p.202), além de ressaltar a importância histórica dos jesuítas na fundação de Salvador e na formação da Bahia desde os tempos de Tomé de Souza e Nóbrega quando construíram o colégio da Bahia com "pedras e cal" (REVISTA SPHAN, 1940, p.201).

Ainda nesse volume aparece o artigo de David Carneiro sobre o Colégio dos Jesuítas de Paranaguá (PR) que fala do "gosto pela pobreza" (REVISTA SPHAN, 1940, p.382) na construção do claustro e destaca duas fotografias do pátio (há indícios de que seja do fotógrafo Erich Hess) e também a importância histórica dos padres jesuítas coloniais na formação histórica e territorial do Paraná.

A revista número 05, de 1941, traz explícito na capa o símbolo dos jesuítas. Em artigo sobre as Capelas Antigas de São Paulo, Sérgio Buarque de Holanda destaca a importância dos jesuítas na formação histórica do território paulista e diz que a Capela Santo Antônio de São Roque (SP) é de "gosto jesuítico que o Sr. Lucio Costa descobriu em alguns de seus ornamentos" (REVISTA SPHAN, 1941, p.116).

Nesse volume aparece o artigo de Lucio Costa intitulado A Arquitetura dos Jesuítas no Brasil onde todo o patrimônio jesuítico tombado entre 1938 e 1941 está presente nesse texto e mesmo o patrimônio a ser tombado nos anos seguintes até 1946 já está listado e discutido por ele. E sobre a arte e os monumentos coloniais Lucio Costa diz que os dos jesuítas "é, contudo, uma das mais significativas e se devêssemos resumir, numa só palavra, qual o traço marcante da arquitetura dos padres, diríamos que foi a sobriedade" (REVISTA SPHAN, 1941). Quando fala sobre os pátios, diz que estes são "modestos e que falta devido ao espírito ativo da Companhia a atmosfera de sossego e de recolhimento e que o pátio de Paranaguá é diferente de todos os demais pátios pelo seu aspecto sombrio e pesado de praça-forte" (REVISTA SPHAN, 1941). Quando fala do programa jesuítico, Lucio diz que é "servido por vários pátios, tudo murado, 


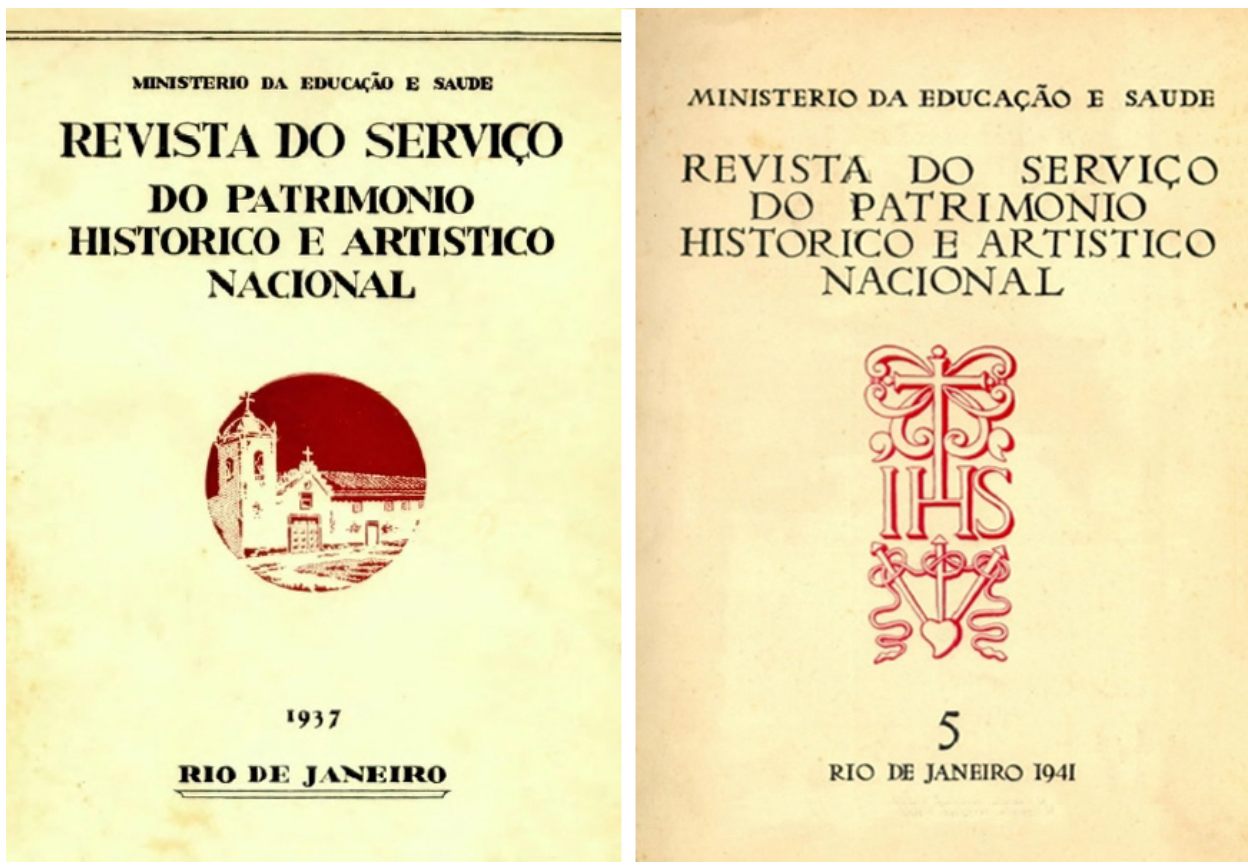

Figura 2: SAIA, Luís. Desenhos da Igreja de São Pedro da Aldeia e Símbolo da Companhia de Jesus. Fonte: Revistas do SPHAN, 01 de 1937 e 05 de 1941. muro que se continuava para os fundos das construções, abraçando a enorme área ocupada" (REVISTA SPHAN, 1941).

Na Revista 06 de 1942 aparece artigo do historiador e padre jesuíta Serafim Leite sobre o Colégio de Santo Alexandre e a Igreja de São Francisco Xavier de Belém do Grão Pará. Nele, Serafim Leite fala sobre o programa, o partido e as técnicas construtivas empregadas no Colégio de Belém desde os primórdios, segundo ele:

uma parede da banda do mar, um pátio da banda da cidade, um muro que cercava o quintal, cerca importante para separar o Colégio das ruas e do bulício, e para poderem repousar os missionários que voltavam de suas missões, casa coberta de telhas, o pátio cercado de um muro de taipa de pilão com suas varandas ao redor sobre colunas, no pátio tudo se faz em breve tempo, o colégio é feito em quadra com muros de pedras e cal. (REVISTA SPHAN, 1942, p.226-227)

Quando Serafim Leite fala do pátio do Colégio de Belém, diz que: "fora de seu recolhimento se aglomeravam oficinas, carpintaria" (REVISTA SPHAN, 1942, p.229) etc, muito similar ao que Lucio Costa e Maria de Lourdes Pontual dizem sobre o programa e o partido jesuítico nas revistas anteriores.

Nesse volume existe ainda um artigo de Ayrton Carvalho intitulado O uso da Pedra na Arquitetura Religiosa do Nordeste onde descreve o uso das pedras como materiais construtivos dos jesuítas coloniais e também enaltece "o arquiteto Lúcio Costa, no valioso trabalho escrito quando das comemorações do centenário da Companhia de Jesus, que distribuiu em quatro períodos os altares construídos, no Brasil, até o século passado" (REVISTA SPHAN, 1942, p.279). 
Na Revista 08 de 1944 existe um artigo de Serafim Leite intitulado Aldeia dos Reis Magos que destaca a importância dos jesuítas na formação histórica do território do Espírito Santo e o preciso e refinado conhecimento de Lucio Costa sobre a arquitetura dos padres inacianos quando diz: "a igreja dos Reis Magos e a Residência anexa é "bem composto" conjunto segundo Lúcio Costa" (REVISTA SPHAN, 1944, p.210).

Como podemos constatar acima, a arquitetura dos jesuítas são recorrentes nas revistas do SPHAN entre 1937 e 1945. Uma arquitetura cujo programa e partido é em quadra com pátio central sóbrio, despojado, modesto, austero, severo, rude, pobre de ornamento externo, simples, linear, de madeira, pedra, cal, areia e barro que significa o multifuncional moderno, o espaço de recolhimento, a durabilidade e o peso de uma arquitetura que é um ícone na história da arquitetura no Brasil, um índice da importância história dos jesuítas na formação do Brasil e um símbolo da memória do patrimônio. Uma arquitetura da aculturação, inculturação, conquista, domínio e conversão. Uma arquitetura do aristotélico-tomismo escolástico e da Ratio Studiorum revisitados nos anos de 1930 e 40. Logo, é valido argumentar que a produção escrita sobre a arquitetura dos jesuítas era um saber produzido pelo SPHAN estado-novista e uma narrativa do patrimônio na legitimação da nação moderna.

O claustro que se transformou em pátio jesuíta era o coração da arquitetura, o centro de tudo, o espaço e elemento centralizador e distribuidor. A quadra com o pátio foram escolhidos como partido e programa da Arquitetura do Regimento de 1548, porque este simboliza e representa a primeira forma de centralização do Brasil. De Ratione Aedifitiorum significa Da Razão e ou Regra da Edificação, e Ratio Studiorum significa Razão e ou Regra de Estudos, a cruz da razão geométrica aristotélica, vitruviana e tomista significa regra, a linha reta regra, logo, a arquitetura deveria responder a essa função de regrar. Era o espaço regrado para a aplicação da razão de um código pedagógico de leis que regem o processo ensino-aprendizagem. O claustro que virou pátio com os jesuítas simboliza a relação intrínseca entre a arquitetura e as ideias aristotélico- tomistas, ou seja, ao ocupá-lo, o sujeito contemplava o significado da cruz, que era a convergência para o centro. A cruz do homem em busca de seu interior. O indivíduo ao praticar os Exercícios Espirituais, aliava o pensamento lógico e racional de raiz aristotélica com a fé cristã, que se completaria com o voltar-se para dentro, para o centro, para o arquétipo do paraíso, para o coração da arquitetura e de si mesmo. Ele é o espaço principal de entrada e articulador de todo o conjunto, e quando a porta principal do colégio está aberta, o signo do espaço multifuncional moderno salta à visão. É a materialização da concepção de universo aristotélicatomista onde a geometria é comum, o quatro é representado pelo retângulo. Um não à decoração supérflua, e um sim a sobriedade, a severidade, a austeridade e a modéstia para obter proporção da centralização, da harmonia e a representação do divino (ENTRINGER, 2015).

O pátio jesuíta significa o modesto, o severo, o sóbrio, o austero, o espaço fechado e murado de pedras que reúne, agrupa, circula, articula e recolhe de forma multifuncional e moderna. Borges (2004) diz que:

ao voltar-se para si, em recolhimento, a Companhia propunha o voltar-se para o mundo, uma vez que ao jesuíta não interessa o recolhimento e o isolamento do claustro, mas a ostensividade e a publicização como meio para converter pagãos e hereges. 
Desse modo, ocorre um deslocamento em relação à aquisição da santidade: esta não se daria mais pela mediação da instituição (o monastério), mas viria em consequência dos exercícios que o devoto praticasse individualmente.

O espaço do recolhimento é indispensável e exposto nos Exercícios Espirituais Inacianos. Segundo o padre, historiador, e colaborador de Costa no SPHAN, Serafim Leite:

o princípio prático dos exercícios era individual, era preciso que houvesse um lugar, um espaço, uma arquitetura em que os Exercícios Espirituais fossem aplicados, e a escolha do sítio para implantação dessas casas eram fundamentais para pôr em prática os exercícios, daí a escolha pelo isolamento, o retiro, a meditação e a contemplação, a busca interna do eu com deus". (LEITE, 1993, p.158)

E embora Costa (SPHAN, 1941) teria dito em seu texto sobre a arquitetura dos jesuítas que "falta devido ao espírito ativo da companhia a atmosfera de sossego e de recolhimento", ele talvez entendesse que o pátio jesuítico era moderno, porque embora aberto, multiuso e centro principal de suas atividades, quando voltava a ser fechado era restrito tais como os pátios das ordem medievais. O pátio jesuíta além de centralizar, regrar, e organizar, é sagrado, ordena, é racional e uma figura geométrica perfeita. Entre 1549 e 1759 os jesuítas o utilizaram porque conquista, defende o território, é uma arma, uma forma de controle social, reduz, segrega, confina, recolhe, dá segurança, educa, e foi o centro do lócus e da base operacional da conquista e do domínio do território. Ora, isso tudo interessa ao Estado Novo, pois legitimava o presente pelo passado e também os usos que se fizeram no passado para aplicação ao presente.

Mas por que por meio das revistas do SPHAN vendiam o recolhimento sóbrio e moderno dos pátios, ou o espírito severo e austero dos jesuítas? Certamente porque é universal e funcional, aplicável em qualquer clima e em qualquer lugar porque ilumina e aquece, tanto o coração da arquitetura ou de quem o adentra e o circula; mas também porque Leonel Franca estava adaptando a antiga Ratio Studiorum aos tempos modernos. Porque ambos, Leonel Franca e Lucio Costa, o aristotélico-tomismo e a Ratio Studiorum servem a função do requerido novo homem moderno e ideal do Estado Novo, aquele que estuda, trabalha, e se recolhe. Uma estratégia para impulsionar a formação e fortalecimento de uma sociedade de cunho urbano-industrial e capitalista. E porque interessava a disseminação da cultura humanística entre as elites, facilitando a sua espiritualização. Confeccionada com uma mistura de aristotélico-tomismo, escolástica, modus parisienses, e Exercícios Espirituais Inacianos, a Ratio Studiorum seria a pedagogia perfeita para isso, porque "proporciona uma rígida formação moral e religiosa, vigilância contínua, concentração, domínio e controle das emoções, firmeza de caráter, sobriedade e obediência irrestrita aos superiores". (FRANCA, 1952)

Quanto aos materiais, técnicas e tecnologias construtivas dos jesuítas, o uso de argamassas com cal vem das arquiteturas árabes e mudéjares presentes na Espanha e em Portugal. Construíam com pedras e madeiras encontradas no lugar. Recorriam a tradição ibérica de construções populares, misturado ao conhecimento técnico e tecnológico dos índios e ao mesmo tempo aproveitando o trabalho como estratégia de educação e conversão. Isso tornavam os jesuítas autônomos e autossustentáveis em matéria-prima construtiva, vernacular e orgânica. 
Figura 3a (esq.): HESS, Erich. Arcada e pátio do antigo Colégio dos Jesuítas de Paranaguá. Fonte: Revista do SPHAN, 04 de 1940.

Figura 3b (dir.): COSTA, Lúcio Desenho do programa jesuítico. Fonte: Revista do SPHAN, 05 de 1941.
Construíam com pedra, cal, barro e madeira porque são materiais resistentes, duros, pesados, sustentável, simples, fácil, rápido e econômico. O modo de produção era voltado a estratégia de aculturação e inculturação, por isso era extrativismo e cooperação. Esses materiais são ícones das técnicas e tecnologias construtivas na história do Brasil, um índice da relação entre tradição e modernidade, um símbolo da aculturação, inculturação, durabilidade, simplicidade, sustentabilidade e economia. Significa a importância do conhecimento da história da técnica e tecnologia construtiva colonial. A pedra, a madeira e o barro eram sagrados tanto para os índios quanto para os jesuítas, e no caso dos inacianos era uma alegoria ao gênesis bíblico. Logo, é válido argumentar que era preciso conhecer, pesquisar e estudar as primeiras técnicas e técnicas e tecnologias construtivas na história do Brasil para legitimar o patrimônio e para o processo de tombamento e restauração e até mesmo para construir uma arquitetura moderna que sofria influência dos trabalhos do SPHAN.

Os jesuítas foram importantes na História do brasil pela formação dos lugares, dos territórios, das cidades e da arquitetura, o pioneirismo no projeto civilizador dos atuais estados brasileiros como Bahia, Espírito Santo, Pará, Rio de Janeiro, São Paulo, Paraná, Rio Grande do Sul, e o valor de sua arte e de sua arquitetura era para o SPHAN uma relíquia e uma genialidade. Isso significa a importância dos Jesuítas para o MEC e SPHAN na preservação do patrimônio e uma exaltação a Vargas e o seu Estado Novo. A Companhia de Jesus é um ícone na história da arquitetura, um índice de importância, e um símbolo do patrimônio da nação.
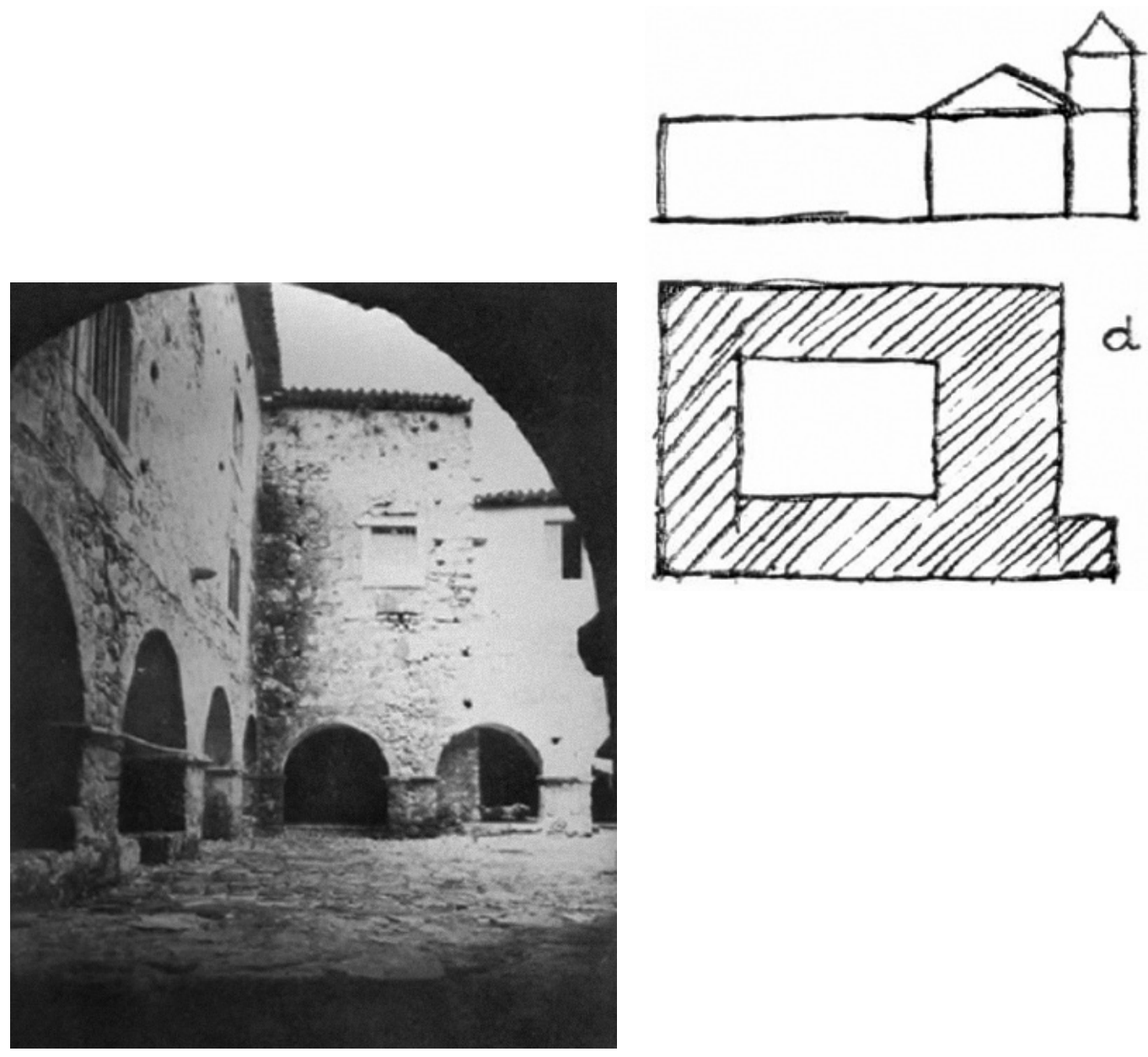
Logo, é válido argumentar que nas revistas do SPHAN entre 1937 e 1945 a arquitetura jesuítica se destaca em relação a outros patrimônios edificados de caráter civil, militar, rural e até mesmo religioso. As revistas dão destaques aos patrimônios que representam a formação histórica da nacionalidade de norte a sul do Brasil e os patrimônios jesuítas caíram como uma luva. Lucio Costa é citado sempre que possível em artigos da revista. Assim, a arte e a arquitetura dos jesuítas tiveram eficácia na narrativa da nação e como mito fundador da ideologia do SPHAN estado-novista.

Mas qual a importância de Lucio Costa para as revistas? Segundo Rubino (2002, p.08), Lucio Costa "foi peça fundamental nas definições da política de salvaguarda da memória nacional, ele elegeu o que tombar, como cuidar e como explicar a obra tombada e incarnou o papel de intelectual total do SPHAN". Isso significa o uso da tradição para justificar o moderno, o equilíbrio entre o plástico colonial e o moderno, o papel do historiador, e os valiosos trabalhos escritos nas revistas. Os materiais, as técnicas e tecnologias construtivas dos jesuítas coloniais e o seu concreto armado moderno, ou os cotejos entre os mobiliários dos mestres europeus modernos com o patrimônio colonial ibérico nas revistas em 1939, o especialista e o perito em história da arquitetura, em especial, a jesuítica, e sua forma de tombamento e preservação. Lucio Costa é um ícone na arquitetura brasileira, um índice da relação entre tradição e modernidade, história e vanguarda, um símbolo do conhecimento, da perícia e da preservação. Isso significa a influência e poder de Costa, o historiador, o arquiteto, o perito, o pesquisador e o restaurador do SPHAN.

Lucio Costa atesta a modernidade dos jesuítas, quando diz que:

foi precisamente esse estilo sóbrio e de formas geométricas definidas, de Herrera em Madri e de Terzi em Lisboa, estilo ali, então, "ultramoderno" e que destoava violentamente da atmosfera local, saturada ainda de reminiscências manuelinas e platerescas, que veio para o Brasil quinhentista, trazido de primeira mão - novo em folha - pelo arquiteto Francisco Dias, colaborador de Terzi na construção de São Roque. (REVISTA SPHAN, 1941)

É claro que o mestre moderno se dedicaria ao estudo da Companhia de Jesus, porque foram os primeiros agenciadores e os pioneiros na introdução de uma arquitetura moderna no Brasil. Constituem nossa antiguidade e nossa antiguidade é moderna. Logo, é valido argumentar que Costa era uma espécie de ideólogo no processo de construção da identidade e um agente decisivo nos tombamentos, nas pesquisas e nos escritos teóricos do SPHAN.

\section{Lucio Costa e a Academia SPHAN: entre a história e a vanguar- da na invenção e na construção da identidade da nação pela modernidade}

Com a Revolução liderada por Getúlio Vargas em 1930 e a nomeação de Lúcio Costa para diretor da EBA, a arquitetura moderna passou a ser acolhida, no Brasil, como uma questão de política nacional (FRAMPTON, 1997). Posteriormente, após sua saída da EBA Lucio Costa projetava, mas, era funcionário do SPHAN, cujo as atividades se iniciaram em 1937, ano em que mergulha na fusão entre o moderno e a tradição (KATINSKY, 1972). Rubino (2002, p.11) argumenta que Lucio Costa 
considera como sendo o início de sua vinculação ao SPHAN "o inventário e o projeto de recuperação das Missões Jesuíticas no Rio Grande do Sul, ou seja, o patrimônio é parte da conversão de Costa, de um início de carreira intelectual marcado pela paixão pela arquitetura colonial".

Lúcio Costa era excelente arquiteto, urbanista e brilhante teórico, tendo sido o responsável pelo casamento dialético entre o velho e o novo que deu o caráter singular da arquitetura brasileira. Para Lucio Costa, ser moderno era "conhecer a fundo o passado, ser atual e prospectivo (CAVALCANTI e LAGO, 2005).

Segundo Martins (2000, p.376):

na concepção de Lucio Costa, que se consolidará como a matriz teórica hegemônica ao longo dos anos quarenta e cinquenta, a arquitetura moderna, antes de ser anti-histórica, é o instrumento de religamento com o "verdadeiro espírito da arquitetura tradicional brasileira". Na tradição arquitetônica do projeto modernista, a identidade não se busca no passado mas que se inventa, se projeta no futuro. (MARTINS, 2000, p.376)

Segundo Nobre:

ao fundir ali as perspectivas do arquiteto e do historiador, Lucio Costa impôs-se o duplo compromisso de projetar nosso futuro e construir nosso passado. E por dar como certa a existência de uma formação cultural primordial, em larga medida transfigurada ou abafada no decorrer do tempo, porém capaz de expressar a identidade brasileira fez da sua longa atuação no SPHAN um meio de recuperá-la por meio de um conjunto de práticas de natureza simbólica revestida de uma autoridade delegada, desde primeira hora, por um governo decidido a investir no projeto de construção da nacionalidade pela via da produção cultural". (NOBRE; KAMITA; CONDURU, 2004, p.127)

Para Rubino, "os homens do SPHAN, dentre eles Lúcio Costa, pensaram com história" (2002, p.17). Puppi (1994, p.124) concorda dizendo que "a forma de estudo histórico reveste de autoridade o programa da arquitetura moderna: Lucio Costa projeta-o na história, reinterpretando-a e reescrevendo-a. Tal estratégia revela-se eficaz, e o arquiteto militante fará larga fortuna como historiador". Silva Telles (1989, p.79), também se posiciona dizendo que: "Lúcio reivindica é um sentimento de brasilidade constituído pela história".

Para Santos (1997, p.91), "a obsessão pela invenção de uma tradição é parte integrante do imaginário modernista que domina a Academia do SPHAN". Para Puppi (1994, p.141-142) era a "construção de uma cultura nacional capaz de conciliar a modernidade com a tradição, e agente da construção da cultura nacional, uma espécie de defesa conservadora das glórias passadas, desse projeto cultural nacionalista, a história está na base do edifício teórico de Lucio Costa".

Segundo Puppi (1994, p.129) mesmo raciocínio aplicado a prática profissional, "Lucio Costa transpunha as tarefas da pesquisa histórica e da preservação do patrimônio. Ao lado da contribuição imediata do estudo da arquitetura tradicional a arquitetura 
moderna, julgava imperativo que a pesquisa e a preservação acompanhassem os mesmo princípios da nova arquitetura". Dias Comas também concorda que a arquitetura de Lucio Costa "é usualmente considerada em função das ideias de uma modernidade assente na tradição e de uma nacionalidade" (NOBRE; KAMITA; CONDURU, 2004, p.19).

Para Silva Telles (1989, p.76 e 89) são "os valores da tradição construtiva da colônia - a simplicidade, a harmonia e a austeridade - que deveriam reger o sentido e a intenção do projeto moderno Lúcio pretende que a consciência aflorada do passado possa conferir sentido ao presente".

A história de um grupo humano é sua memória coletiva, porque dá-lhe um sentido de identidade (FONTANA, 1998). Segundo Hobsbawm (2000, p.17) "a história é a matéria prima para as ideologias nacionalistas. O passado é um elemento essencial nessas ideologias. Se não há nenhum passado satisfatório, sempre é possível inventa-lo. O passado legítima, fornece um pano de fundo mais glorioso a um presente que não tem muito que comemorar". Complementa Le Goff (1990, p.15) que "cada época fabrica mentalmente a sua representação do passado histórico". E Lucio Costa ajudou a fabricar seu tempo.

O modernismo, por exemplo, movimento revolucionário que ditava regras na época e que se inseria ideologicamente tanto nos intelectuais do MEC quanto nos do SPHAN, é um movimento fundamental de uma redefinição, de uma nova imagem da cultura brasileira no século XX. Era o reinventar os princípios da cultura brasileira para o momento presente, sendo um projeto estético fundamentalmente nacional, no qual era exaltada a herança da península ibérica, o iberismo como um projeto político e algo que se constrói para viabilizar a ordem moderna e constitutiva da nação existente (ROCHA, 2012).

Por isso que "temos que desmontar e desconstruir a Era Vargas, período histórico peculiar e de extraordinária importância para se pensar o contemporâneo. Fazer da questão ibérica um instrumento intelectual ainda interessante para se pensar o Brasil de hoje" (NOGUEIRA, 2003). E Lúcio Costa era o homem cordial ibérico a negociar nossa modernização entre o rural colonial e o moderno urbano.

O SPHAN era subordinado ao MEC, e segundo Wisnik (2007, p.170), "o aparelho de Estado, constituiu uma política de patrimônio" e o SPHAN representou bem isso. Os chamados patrimônios históricos e artísticos têm nas modernas sociedades a função de representar simbolicamente a identidade e a memória da nação. Durante esse período o SPHAN norteou sua política pelas noções de tradição e de civilização, dando especial ênfase à relação com o passado. Essa apropriação do passado era concebida como um instrumento para educar a população a respeito da unidade e permanência da nação (CPDOC-FGV).

Segundo Santos (1997, p.78), "a Academia SPHAN nasce ancorada na ideia básica que é o registro da nação". Rubino (2002, p.08) corrobora argumentando que "o SPHAN iniciou os tombamentos de bens que fazem parte da narrativa da nação". Guerra Neto $(2002$, p.114) também partilha dessa mesma informação de que "ao se buscar no passado a legitimidade do presente, a equipe do SPHAN desencadeia uma ação preservacionista que, privilegiando a história, dignifica a tradição como patrimônio, e forma a própria essência de nação".Acrescentamos aqui, que não só Lucio Costa 
foi peça fundamental no avanço conservador, religioso, industrial e moderno e na política de salvaguarda da memória e identidade, mas dois outros personagens de grande importância são agrupados a ele: Serafim Leite, o historiador, historiógrafo e ideólogo da Igreja e do Estado atuando via SPHAN, e Leonel Franca, padre e professor jesuíta, vice-reitor do Colégio Santo Inácio, reitor e um dos fundadores da PUC-RJ e sua Ratio Studiorum modernizada atuando na Universidade.

Assim, no SPHAN, Lucio Costa teve parcerias com políticos, historiadores, artistas, intelectuais, arquitetos e fotógrafos. As revistas do SPHAN eram escritas por intelectuais polímatas a exemplo do próprio Lucio Costa (arquiteto, professor, historiador, perito e restaurador), Rodrigo Melo Franco de Andrade (advogado, jornalista, escritor e diretor do SPHAN e depois IPHAN), Mario de Andrade (poeta, escritor, crítico literário, musicólogo, folclorista, e ensaísta), Gilberto Freyre (escritor, ensaísta, sociólogo, antropólogo, historiador, jornalista, poeta e pintor), Godofredo Filho (poeta, escritor, professor e futuro diretor do IPHAN), Joaquim Cardoso (poeta, contista, engenheiro civil, desenhista, editor e professor), Luís Saia (arquiteto e desenhista), Noronha Santos (historiador), David Carneiro (engenheiro, historiador, escritor, poeta), Maria de Lourdes Pontual (funcionária do SPHAN), Alberto Lamego (historiador e geólogo), Serafim Leite (historiador e padre jesuíta), Ayrton de Carvalho (arquiteto), Sérgio Buarque de Holanda (historiador, crítico literário e jornalista) e Romulo Barreto de Almeida (professor, intelectual e político), e do tripartido de intelectuais modernistas interpretes da história do Brasil, dois deles, Gilberto Freyre e Sérgio Buarque de Holanda estão colaborando com a revista, isso tudo pela sua característica pioneira.

No que tange as relações entre Lucio Costa e os fotógrafos do SPHAN que fotografaram a arquitetura jesuítica é preciso destacar o que a fotografia representava para Lucio Costa, segundo ele:

a fotografia é, para mim, um mundo desconhecido e a simples vista da sua apareIhagem me inspira respeito e temor. É pois como leigo que me atraem as imagens registradas pelas máquinas antigas, e que aprecio a foto-documento ou o instantâneo onde o acaso intervém e fixa para sempre um momento único que não poderá jamais ser reconstituído exatamente igual. (FONSECA e CERQUEIRA in LIMA, MELHEM e CUNHA, p.13)

Isso significa que a objetividade fotográfica, enquanto documento, prova, testemunho, reconstrução da memória e da história era um instrumento de pesquisa importante para Lucio Costa na preservação do patrimônio. Sabemos que entre os anos de 1937-1945 os fotógrafos Erich Hess e Silvanísio Pinheiro fotografaram a arquitetura jesuítica em Sergipe e na Bahia. Nota-se que durante os primórdios da fase heroica do IPHAN, Erich Hess foi quem mais fotografou o patrimônio edificado pelos jesuítas. Hess fotografou em Sergipe, na Bahia, no Espírito Santo, no Rio de Janeiro, no Paraná e no Rio Grande do Sul. Há mais três fotógrafos que clicaram o patrimônio jesuítico, sendo ele Silvanísio Pinheiro em Sergipe e na Bahia, Herman Graeser vulgo Germano fotografou em São Paulo, e Edno Pacheco fotografou o Rio Grande do Sul. O próprio Lúcio Costa, relaciona fotógrafos que teriam contribuído com o SPHAN, destacando "o notável Pinheiro e o simpático Erich Hess, disposto a voar fosse para onde fosse." (COSTA, 2016, p.01).

E como "o bom arquiteto é um fotógrafo em espírito, mesmo quando não o é de fato, pois ele se desloca mentalmente em torno de seu edifício ainda imaginário e avalia 

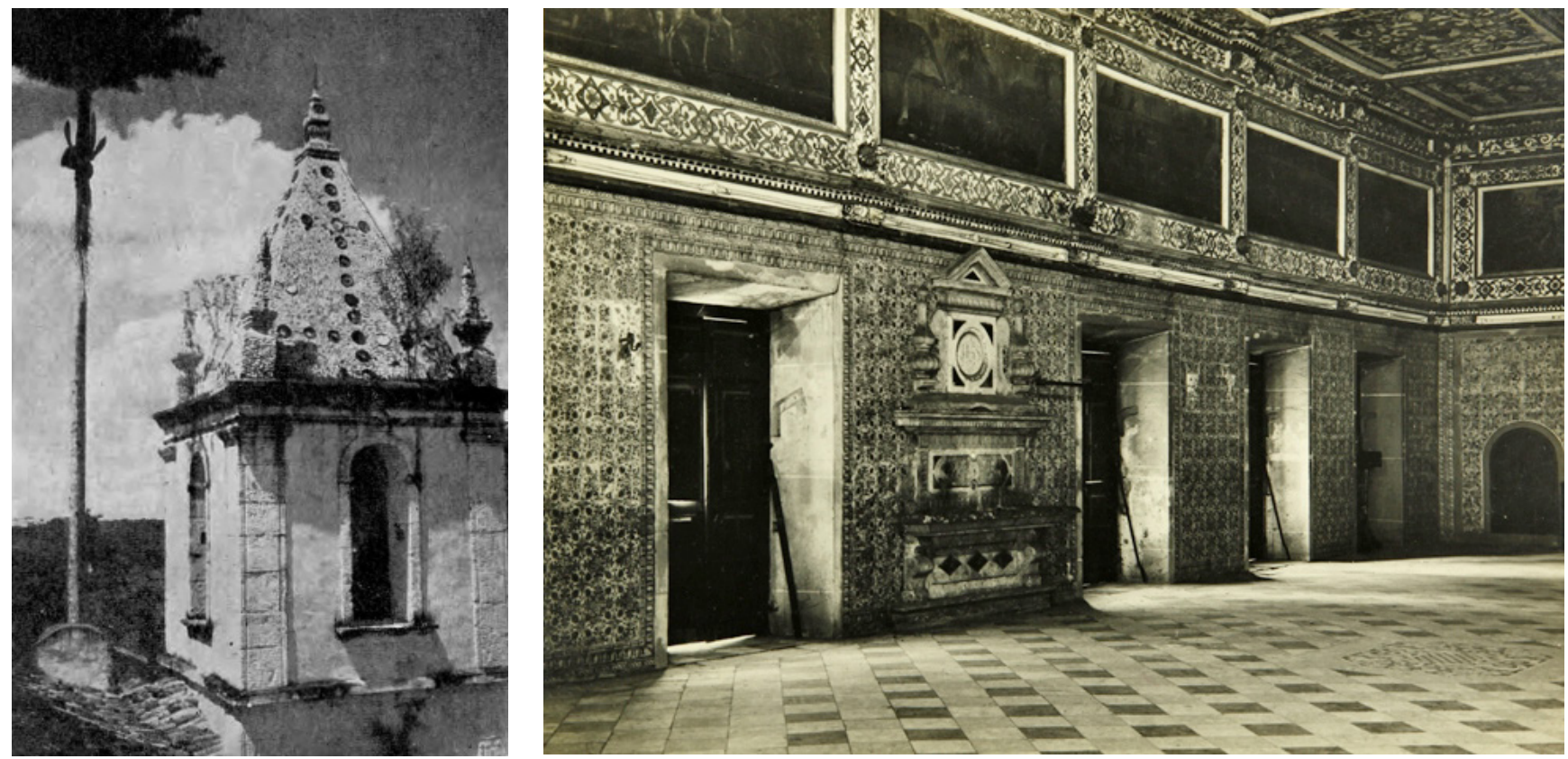

Figura 4a (esq.): HESS, Erich Torre do Seminário de Belém da Cachoeira, BA. Fonte: Revista do SPHAN 01 de 1937.

Figura 4b (dir.): PINHEIRO, Silvanísio. Sacristia da Igreja dos Jesuítas de Salvador - 1940. Fonte: Revista SPHAN 4 de 1940 - Arquivo do IPHAN - Documento fotográfico F002995. todos os pontos de vista possíveis" (VASQUEZ in LIMA, MELHEM e CUNHA, 2008, p.78), Erich Hess - um dos primeiros fotógrafos contratados pelo SPHAN - recebeu do arquiteto Lucio Costa, desenhos com detalhes de monumentos a serem fotografados (GRIECO, 2015), muitos deles jesuíticos.

Fonseca e Cerqueira (in LIMA, MELHEM e CUNHA, p.15-24-26), relatam mais detalhadamente as relações entre Lucio Costa e os fotógrafos do SPHAN:

a produção e a divulgação desse saber fotográfico era considerada tão importante quanto os próprios tombamentos ou obras, pois era sobre esses conhecimentos que assentava toda a prática do órgão. Eram as fotografias que viabilizavam os estudos dos bens culturais espalhados pelo Brasil, objetos de análise para tombamento. A documentação fotográfica também se tornou imprescindível para fins de estudo das obras de conservação e restauração propostas pelo SPHAN, bem como para a verificação dos trabalhos executados e, ainda, instrumentos de consulta e pesquisa por parte dos técnicos do Serviço e pesquisadores do patrimônio cultural brasileiro. Desde 1937, os funcionários e os fotógrafos contratados pelo SPHAN contribuíram para a sua proteção oficial, mas, sobretudo, construindo uma memória fotográfica da cultura brasileira. Muitos tombamentos eram feitos baseados na análise destas fotografias, dada a dificuldade de acesso às diversas localidades do Brasil e, por vezes, às limitações financeiras, que impediam os técnicos de irem a campo. Daí a importância da prática fotográfica naquele momento, funcionando como um instrumento que aproximava os técnicos do SPHAN dos bens arquitetônicos encontrados no Brasil, a serem tombados ou restaurados. Os fotógrafos, geralmente, recorriam aos arquitetos locais que os acompanhavam e orientavam o trabalho fotográfico. Em 1949, Lucio Costa, no plano de trabalho, indicava que os trabalhos de levantamento fotográfico deveriam ser realizados pelos próprios técnicos do SPHAN a partir de treinamen- 
tos com fotógrafos profissionais orientados pelas próprias regionais. Além disso, dizia Lucio Costa que cada distrito deverá possuir um aparelho Leica, ou similar, completo, e contratar com fotógrafo competente, um curso prático de fotografia com o propósito de fazer de cada um dos funcionários técnicos da repartição um fotógrafo habilitado, capaz de fazer a sua própria documentação nas viagens de reconhecimento, pesquisa ou inspeção.

Foto-documento, instantâneo, momento único, máquinas Leica, anos 30 e 40, são indícios de que uma possível influência de Henry Cartier-Bresson chegou até o Brasil, assim sendo, é valido argumentar que Lucio Costa ajudou a construir um olhar sobre a fotografia de arquitetura no SPHAN e também a construir uma fotografia moderna que foi instrumento e parte da elaboração da identidade nacional entre os anos de 1937 a 1945.

Alguns intelectuais do SPHAN, em especial, Lucio Costa e Serafim Leite, produziram trabalhos que parecem ser inspirados na historiografia do final do século XIX e início do XX, ou seja, o cientificismo e positivismo rankeano, história linear, factual, elitista, biografista, a serviço da moralidade da República e da Ordem. Uma escrita da história que parece ter muito em comum com Ernest Lavisse e o nacionalismo francês na operação historiográfica, onde a tarefa do historiador, do arquiteto e do professor, durante os cursos com seus alunos obedientes era "formar republicanos conscientes e soldados valentes" (BOURDÉ; MARTIN,1983, p.110).

No que tange a obra de Serafim Leite, ela é herdeira de uma tradição historiográfica na qual a História é concebida como a biografia do Estado-nação e cujo discurso coloca os jesuítas como nada menos do que coparticipes da fundação desse Estado-nação. Barra diz que "esse discurso influenciou a atuação do SPHAN nos seus primeiros tempos" (CHUVA, 2008, p.61-75).

Roger Keesing "mostrou que a cultura pode ser, entre outras coisas, um modo de mascarar e sustentar poderes e privilégios, de ocultar a exploração e a opressão. Apontou também que é preciso sempre perguntar quem cria e define os significados culturais e com que finalidade" (CARDOSO; VAINFAS, 1997, p.49). Ora, senhores, quem mascarava e sustentava poderes e privilégios e ocultava a exploração e a opressão era a máquina estatal autoritária, católica, industrial, que amórfica, se intitulava moderna, sendo o MEC e o SPHAN quem criava e definia os significados culturais para essas finalidades. Os intelectuais do SPHAN tinham um poder que podemos classifica-lo como sendo "o poder visto como objeto da investigação/produção histórica e o poder enquanto agente instrumentalizador da própria oficina da história, com o que o conhecimento histórico se converte em seu objeto" (FALCON, 1997, p.97.)

É preciso levantar o véu, a batina ou a farda da história pois "toda pesquisa historiográfica se articula com um lugar de produção sócio econômico, político e cultural e "existe um saber histórico dentro de um lugar" (CERTEAU, 2002, p. 62), esse lugar era o SPHAN. Entre o saber e o lugar se ajustam os enquadramentos das pesquisas. O lugar (SPHAN) torna-se uma arena dentro de um jogo hierárquico, de interesses ideológicos e políticos nacionais (Estado Novo, Industrialização e a Igreja Católica), e o produto final são os tombamentos da maior parte do patrimônio jesuítico e as revistas do SPHAN entre 1937 e 1945, que se enuncia num conjunto de práticas do estudo particular que é reconhecida pelo lugar e pelo público que o recebe. 
Lucio teve um traço singular do campo arquitetônico brasileiro, pois, ao mesmo tempo que revoluciona as formas de vanguarda, funda um instituto para preservação das formas pretéritas. Deve-se a Lucio Costa o estabelecimento de uma relação estrutural e dialética entre a arquitetura do presente e do passado, como por exemplo, o Museu das Missões em 1937. Assim, o antigo "passa a ser objeto de restaurações que fazem questão de não esconder as intervenções modernas" (CAVALCANTI e LAGO, 2005).

\section{Conclusão}

Barra diz que para Rodrigo Melo Franco de Andrade, diretor do SPHAN, o Brasil era não apenas o seu território e sua população, mas também, e principalmente, a "obra de civilização" que nele vinha sendo desenvolvida desde os começos da colonização portuguesa. E, como relatamos acima, os jesuítas foram os pioneiros na chamada "civilização" do Brasil. Fica claro entender então porque dentre os primeiros tombamentos e os escritos das primeiras revistas realizados pelo SPHAN muitos eram jesuíticos e porque os anos entre 1937 e 1945 foi o período em que mais se tombou edificações jesuíticas.

O patrimônio materializava essas narrativas (CHUVA, 2008, p.62-69). Ora, se as revistas do SPHAN, sob a consulta de Lucio Costa e grande parte de seus intelectuais ou funcionários estavam envolvidos e divulgando os signos do patrimônio jesuíta e dando destaque aos inacianos em suas revistas, o seu diretor, Rodrigo Melo Franco de Andrade não poderia estar fora dessa empreitada. E o índice disso seria a fotografia (figura 5) de Erich Hess feita em 1939 da Igreja da Camandaroba de 1734 e que pertenceu aos padres da Companhia nas planícies de Laranjeiras (SE), tombada em 1943, e inscrita sob número 207 no livro Histórico e 272-A no Livro de Belas Artes.

Nessa fotografia aparece em primeiro plano as estruturas construtivas, os barrotes, escadas, guarda-corpos, caibros e pilares de madeira, a arcada de pilares clássico de pedra, areia e barro caiados bem ao gosto jesuítico; e no centro e no fundo aparecem sentados numa janela-conversadeira e num contraluz de uma luz difusa e suave que irradia e entra pelo centro do arco romano clássico, Rodrigo Melo Franco de Andrade com quem supomos ser a Sra. Sobral, proprietária da Igreja da Camandaroba.

Mas porque o interesse, a prioridade e a urgência de Rodrigo Melo Franco de Andrade na Igreja da Camandaroba? Porque o diretor do SPHAN se deslocaria de seu gabinete no Rio de Janeiro para ir até o interior de Sergipe? Seriam porque as notificações enviadas por Rodrigo aos proprietários da Igreja e tendo ele recebido apenas cartas dizendo que os proprietárias haviam recebido as notificações mas não autorizando o tombamento como informa o processo de tombamento do SPHAN n0299-T-41? Acreditamos que não só; mas também acresce a isso o interesse em tombar o patrimônio de quem estava no centro e por detrás do governo Vargas, do Ministério da Educação e da Cultura de Capanema, e do Serviço do Patrimônio Histórico e Artístico Nacional de Rodrigo Melo Franco de Andrade e Lúcio Costa, ou seja, os jesuítas e sua Companhia. 

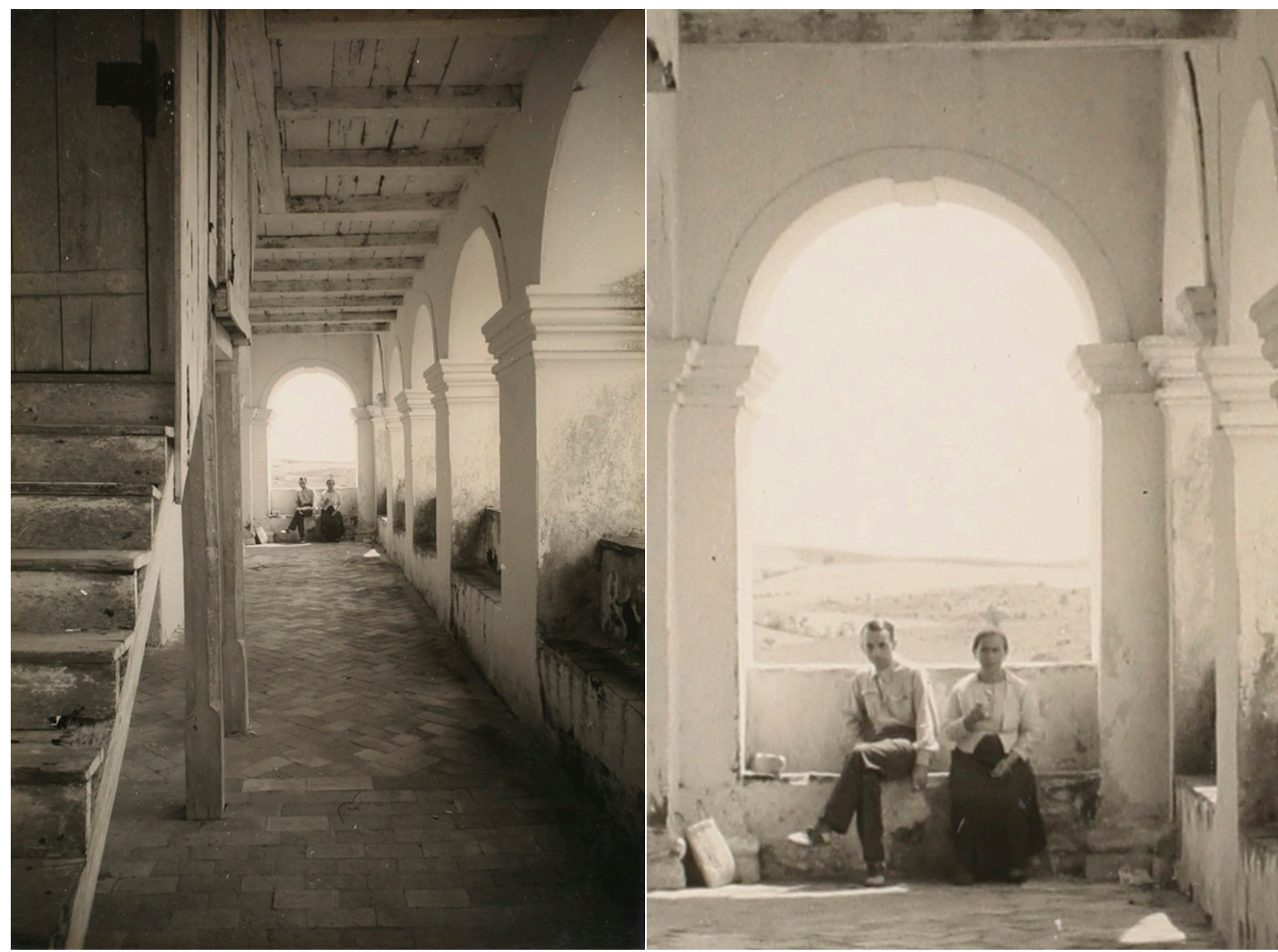

Figura 5: HESS, Erich. Rodrigo Melo Franco de Andrade com quem acreditamos ser a Sra. Sobral proprietária da Igreja da Camandaroba em Laranjeiras, SE - 1939. Fonte: Documento fotográfico do IPHAN número F024606.
Como vimos, numerosos foram os artigos que tratavam do patrimônio de origem jesuíta. Segundo Menezes: "para os intelectuais do SPHAN, a contribuição dos jesuítas à formação da nacionalidade e de nosso território deveria ser valorizada através da arquitetura. 0 que deveria ser protegido como legado da Companhia de Jesus para a memória do Brasil era o seu modo de construir" (CHUVA, 2008, p.13-27). Por fim, Chuva (2008, p.16-34) diz que "o artigo de Lucio Costa, publicado pela revista na década de 1940, é um exemplo do que se buscava com a Revista, ou seja, a relação entre a agência de proteção do patrimônio e os resquícios da presença jesuítica se deu pela eleição de símbolos que contassem a história da nação e refundassem seu mito de origem pela influência do movimento modernista".

Assim sendo, não poderíamos deixar de concluir com Hobsbawm (2000, p.47-48) quando diz que: "a história como inspiração e ideologia tem uma tendência embutida a se tornar mito de auto justificação. Não existe venda para os olhos mais perigosa do que essa". Logo, é valido argumentar que, no Brasil, a modernidade, talvez pela nossa herança portuguesa colonial, teve que pedir as bênçãos da Igreja, e os intelectuais do SPHAN, entre eles, Lucio Costa, utilizaram os signos dos jesuítas para permitir à sociedade estado-novista representar a si mesma, legitimar a pioneira arquitetura moderna, fundar a identidade nacional e delinear a ideia de uma República justificada pela história. 


\section{Referências bibliográficas}

BORGES, Luiz C. As Línguas Gerais e a Companhia de Jesus - Política e Milenarismo. Cadernos de Estudos Linguísticos 46(2). Campinas. Jul./Dez. 2004, p.171-194.

BOURDÉ, Guy; MARTIN, Hervé. As Escolas Históricas. Lisboa: Fórum da História/Publicações Europa América, 1983.

CARDOSO, Ciro, Flamarion; VAINFAS, Ronaldo (Orgs.). Domínios da História: ensaios de teoria e metodologia. Rio de Janeiro: Editora Campus, 1997.

CAVALCANTI, Lauro; LAGO, André Corrêa do. "Ainda moderno? Arquitetura brasileira contemporânea." Arquitextos n. 6, no. 066.00 (Nov. 2005).

CERTEAU, Michel. A Escrita da História. Rio de Janeiro: Forense Universitária, 2002.

CHUVA, Márcia (org.). Assentamentos jesuíticos: territórios e significados. Rio de Janeiro: IPHAN/Copedoc, 2008.

COSTA, Eduardo Augusto. Uma trajetória do Arquivo Fotográfico do Iphan: mudanças discursivas entre os anos 1970 e 1980. São Paulo: Anais do Museu Paulista, vol.24 no.1, Jan./Apr, 2016.

CUNHA, Oscar Henrique Liberal de Brito e (Coords.). A Fotografia na preservação do patrimônio cultural: uma abordagem preliminar. Cadernos de Pesquisa e Documentação do IPHAN. COPEDOC/IPHAN, Rio de Janeiro, 2008.

ENTRINGER, Rogério. A Cruz e a Quadra na Arquitetura dos Jesuítas no Brasil: um discurso fotográfico. São Carlos: Dissertação de Mestrado IAU-USP, 2015

FALCON, Francisco. História e Poder. In: CARDOSO, Ciro, Flamarion; VAINFAS, Ronaldo (Orgs.). Domínios da História: ensaios de teoria e metodologia. Rio de Janeiro: Editora Campus, 1997.

FONSECA, Brenda Coelho; CERQUEIRA, Telma Soares. Mapeamento preliminar das atividades dos Fotógrafos no IPHAN (1937-1987). In: LIMA, Francisca Helena Barbosa; MELHEM, Mônica Muniz; CUNHA, Oscar Henrique Liberal de Brito e (Coords.). A Fotografia na preservação do patrimônio cultural: uma abordagem preliminar. Cadernos de Pesquisa e Documentação do IPHAN. COPEDOC/IPHAN, Rio de Janeiro, 2008.

FONTANA, Josep. História: análise do passado e projeto social. Bauru: Edusc, 1998, p.267).

FRAMPTON, Kenneth. História Crítica da Arquitetura Moderna. São Paulo: Martins Fontes, 1997.

FRANCA S.J., Leonel. O método pedagógico dos jesuítas: o "Ratio Studiorum": Introdução e Tradução. Rio de Janeiro: Livraria Agir Editora, 1952.

GUERRA NETO, Abílio da Silva. Lúcio Costa: modernidade e tradição - montagem discursiva da arquitetura moderna brasileira. São Paulo, 2002.

HOBSBAWM, Eric. Sobre História. São Paulo: Companhia das Letras, 2000.

KATINSKY. Júlio Robert. Lucio Costa. São Paulo: Revista do IEB - USP, n12, 1972.

LE GOFF, Jacques. A História Nova. São Paulo: Martins Fontes, 1990.

. História e Memória. Campinas: Editora da UNICAMP, 1990.

LEITE, Serafim. Breve História da Companhia de Jesus no Brasil (1549-1760). Braga, Portugal: Livraria A.I, 1993.

MARTINS, Carlos A. F. Construir una Arquitectura, Construir um País. In: SCHWARTZ, Jorge (Org.). Brasil, 1920-1950: De la AntropofAgia a Brasilia. Valencia: IVAM - Institut Valecià d'Arte Modern, 2000. p. 371 - 381. 
NOBRE, Ana Luiza; KAMITA, João Masao; CONDURU, Roberto. (orgs.). Um modo de ser moderno: Lucio Costa e a crítica contemporânea. São Paulo: Cosac \&Naify, 2004.

NOGUEIRA, Marco Aurélio. Positividades e negatividades da herança Ibérica. Conferência em Intérpretes do Brasil. Campinas: Espaço Cultural CPFL/ TV Cultura, 2003. Disponível em <https://www.youtube.com/watch?v=DLvsGLRM-Fl> Acesso em 20/03/2017.

REVISTA DO SPHAN. Rio de Janeiro: Ministério da Educação e da Saúde, n.01, 1937. Rio de Janeiro: Ministério da Educação e da Saúde, n.02, 1938. Rio de Janeiro: Ministério da Educação e da Saúde, n.03, 1939. Rio de Janeiro: Ministério da Educação e da Saúde, n.04, 1940. Rio de Janeiro: Ministério da Educação e da Saúde, n.05, 1941. Rio de Janeiro: Ministério da Educação e da Saúde, n.06, 1942. Rio de Janeiro: Ministério da Educação e da Saúde, n.08, 1944.

ROCHA, João C. de C. Debate "Antropofagia e atualidade". Comemorações 90 anos da Semana de Arte Moderna de 1922. Faculdade de Direito da USP. São Paulo, 2012. Disponível em <https://www.youtube.com/watch?v=KbfJQvV4erw> Acesso em 20/04/ 2017.

RUBINO, Silvana. Lucio Costa e o Patrimônio Histórico e Artístico Nacional. In: REVISTA USP, São Paulo, n.53, março/maio 2002, p. 6-17.

SANTOS, Mariza Veloso. Nasce a Academia SPHAN. Revista do Patrimônio Histórico e Artístico Nacional, n² 24. Rio de Janeiro, 1997.

SILVA TELLES, Sophia da. Lucio Costa: monumentalidade e intimismo. In Novos Estudos/CEBRAP no 25. São Paulo, 1989. p.75-94.

VASQUEZ, Pedro Afonso. Construções mentais e imagens reais - Notas sobre o diálogo entre arquitetura e fotografia. In: LIMA, Francisca Helena Barbosa; MELHEM, Mônica Muniz; CUNHA, Oscar Henrique Liberal de Brito e (Coords.). A Fotografia na preservação do patrimônio cultural: uma abordagem preliminar. Cadernos de Pesquisa e Documentação do IPHAN. Rio de Janeiro: COPEDOC/IPHAN, 2008.

WISNIK, Guilherme. Plástica e anonimato: modernidade e tradição em Lucio Costa e Mário de Andrade. Novos Estudos - CEBRAP, n.79, 2007, p. 169- 193. 